\title{
Analysis and Comparison of Push-Pull Class-E Inverters with Magnetic Integration for Megahertz Wireless Power Transfer
}

\author{
Huang, Xiaosheng; Kong, Yipeng; Ouyang, Ziwei; Chen, Wei; Lin, Shuyi
}

Published in:

IEEE Transactions on Power Electronics

Link to article, DOI:

10.1109/TPEL.2019.2915770

Publication date:

2020

Document Version

Peer reviewed version

Link back to DTU Orbit

Citation (APA):

Huang, X., Kong, Y., Ouyang, Z., Chen, W., \& Lin, S. (2020). Analysis and Comparison of Push-Pull Class-E Inverters with Magnetic Integration for Megahertz Wireless Power Transfer. IEEE Transactions on Power Electronics, 35(1), 565-577. https://doi.org/10.1109/TPEL.2019.2915770

\section{General rights}

Copyright and moral rights for the publications made accessible in the public portal are retained by the authors and/or other copyright owners and it is a condition of accessing publications that users recognise and abide by the legal requirements associated with these rights.

- Users may download and print one copy of any publication from the public portal for the purpose of private study or research.

- You may not further distribute the material or use it for any profit-making activity or commercial gain

- You may freely distribute the URL identifying the publication in the public portal 


\title{
Analysis and Comparison of Push-Pull Class-E Inverters with Magnetic Integration for Megahertz Wireless Power Transfer
}

\author{
Xiaosheng Huang, Yipeng Kong, Ziwei Ouyang, Senior Member, IEEE, Wei Chen, and Shuyi Lin
}

\begin{abstract}
This paper presents the circuit design and magnetic integration of push-pull class-E inverters for wireless power transfer (WPT) up to megahertz. The design criterion for achieving ZVS of a class-E inverter with coupled windings is derived mathematically. The approaches of magnetic integration for push-pull class-E inverters are analyzed and compared. Then, a new magnetic structure with hybrid magnetic materials is proposed to build the integrated inductors with either coupled windings or uncoupled windings. A 3 MHz WPT system is built to verify the analysis. The detailed comparison of the class-E inverters with magnetic integration is presented in terms of switch voltage, efficiency, harmonic currents and thermal distribution. In the optimized design example, the switches keep ZVS over the entire load range without using any closed-loop control. The system efficiency reaches $87.1 \%$ at $350 \mathrm{~W}$ output power.
\end{abstract}

Index Terms-wireless power transfer, class-E, integrated magnetic, inverter, rectifier

\section{NOMENCLATURE}

$v_{S}, v_{S 1}, v_{S 2}$ Switch voltages.

$\omega \quad$ Angular frequency.

$R \quad$ Equivalent load resistance of inverters.

$i_{R} \quad$ Output current of the inverter.

$I_{R} \quad$ Amplitude of $i_{R}$.

$\varphi \quad$ Initial phase of $i_{R}$.

$Q_{L} \quad=\omega L_{o} / R$, loaded quality factor.

$L_{i n} \quad$ Inductance of winding $L_{i n 1}$ and $L_{i n 2}$.

$L_{c} \quad$ Mutual inductance of the coupled windings.

$L_{f} \quad$ Leakage inductance of the coupled windings.

$k_{i n} \quad$ Coupling coefficient of the coupled windings.

$i_{\text {in } 1}, i_{i n 2} \quad$ Winding current.

$I_{D C} \quad$ DC component, i.e., DC bias of $i_{i n 1}, i_{i n 2}$.

$i_{L f} \quad$ AC component of $i_{i n 1}, i_{i n 2}$.

$C_{f} \quad$ capacitance of $C_{f 1}, C_{f 2}$.

$L_{e} \quad=2 L_{f}$, equivalent resonant inductance for the coupled windings.

$V_{\text {in }} \quad$ Input DC voltage.

$q_{e} \quad=1 / \omega \sqrt{L_{e} C_{f}}$, the normalized resonance frequency of $L_{e}$ and $C_{f}$.

This work was supported supported by the National Natural Science Foundation of China (51607039), Natural Science Foundation of Fujian Province of China (2018J01623).

Xiaosheng Huang, Yipeng Kong and Shuyi Lin are with the College of Information Science and Engineering, Fujian University of Technology, Fuzhou 350118, China. (e-mail: hxs@ @ fjut.edu.cn; kongyipeng1992@qq.com; linshuyi1985@qq.com).

Ziwei Ouyang is with the DTU Electro, Technical University of Denmark, 2800 Kongens Lyngby, Denmark(e-mail: zo@elektro.dtu.dk).

Wei Chen is with the College of Electrical Engineering and Automation, Fuzhou University, Fuzhou 350118, China. (e-mail: chw@fzu.edu.cn).

$\begin{array}{ll}p_{e} & =I_{R} \cdot \omega L_{e} / V_{i n}, \text { the normalized output current. } \\ p_{r e} & =R / \omega L_{e}, \text { the } R \text { normalized by the reactance } \\ & \text { of } L_{e} \cdot \\ & =v_{S} / V_{i n} \text { the normalized switch voltage. } \\ v_{S n} & \text { Initial value of } i_{i n 1} \text { at } \omega t=\pi . \\ I_{L \pi} & =I_{L \pi} \cdot \omega L_{e} / V_{i n}, \text { the normalize } I_{L \pi} . \\ p_{\pi e} & q=1 / \omega \sqrt{L_{f} C_{f}}=\sqrt{2} q_{e}, \text { the normalized } \\ q & \\ & \text { resonance frequency of } L_{f} \text { and } C_{f} . \\ & =I_{R} \cdot \omega L_{f} / V_{i n}=\frac{1}{2 p_{e}}, \text { the normalized output } \\ & \text { current. } \\ & =R / \omega L_{f}=2 p_{r e}, \text { the } R \text { normalized by the } \\ p_{r} & \text { reactance of } L_{f} \cdot \\ & =L_{i n}, \text { resonant inductance for the uncoupled } \\ L_{d e c p l} & \text { windings. } \\ & =L_{f}, \text { resonant inductance for the coupled } \\ L_{c p l} & \text { windings. }\end{array}$

\section{INTRODUCTION}

Wireless power transfer (WPT) based on magnetic coupling is increasingly applied in portable devices, medical implants, electric vehicles and so on [1]-[5]. In most common situations, increasing the frequency is conducive to reduce the size and extend the transfer distance, but it is quite challenging to design a high-efficiency inverter for the WPT up to megahertz. The efficiency deteriorates because of the substantial increase in the losses of switches and magnetic components.

A class-E inverter with finite DC-feed inductance is often used for the WPT of which the load varies in a wide range. The switch can naturally achieve zero-voltage-switching (ZVS) without using closed-loop control, but this expected feature is essentially based on using much lower input inductance [6][8]. It results in a large AC current through the input inductor and the DC source. The current causes not only additional losses but also conducted electromagnetic interference (EMI).

Interleaving two class-E inverters is effective for suppressing the odd-order harmonics through the DC source. The combined topology is known as push-pull class-E inverter [9], [10], differential-mode class-E inverter [11]. The even-order harmonics remaining can also be reduced by coupling the input inductors of the interleaved inverters. Hence, the ripple current through the DC source can be suppressed significantly to reduce EMI noise. This approach was introduced in [12], but the design criterion to achieve ZVS was still unclear.

In the push-pull class-E inverter with finite DC-feed inductance, the amplitude of the AC current through the input 
inductors is kept relatively large to maintain ZVS when the load varies. For loss reduction, a possible approach is reducing the amplitude by an adjustable input voltage, but it requires an additional DC-DC converter [13]. The other approach is reducing the ESR (equivalent series resistance) of the inductors by using a larger size of the magnetic elements. Consequently, individual inductors with air-core or low-permeability cores are usually applied in the class-E inverters. The inductor size is relatively big and difficult to be reduced.

The design methodologies of the inductors of class-E inverters are basically the same as conventional power converters. [14] proposes a detailed design method of choke inductors for parallel-capacitor class-E inverters, but it cannot be used for the inductor with a large AC current. [15] introduces a design method to reduce the volume of inductors with significant AC current. However, by now, most existing literatures about class-E inverters focus on the circuit design and closed-loop control, but not the magnetic design [6], [8], [16]-[21].

Magnetic integration methods, particularly coupling multiple inductors, have been proved highly effective for improving performance and reducing the size of power converters [22][24]. When the two inductors of a push-pull class-E inverter are integrated, the circuit board area occupied by the inductors can be reduced directly. Moreover, the class-E inverter presents improved harmonic suppression by coupling the inductor windings. However, so far, few studies have discussed the magnetic integration of class-E inverter.

This paper presents the circuit design and magnetic integration of push-pull class-E inverters for the WPT up to megahertz. The circuit analysis, design and comparison of the class-E inverters with either coupled or uncoupled windings are first presented in section II. It shows that the evenorder harmonic currents through the integrated inductor are suppressed by coupling the windings. Then, a design criterion to satisfy ZVS of the push-pull class-E inverter with coupled windings is proposed. In section III, the approaches of magnetic integration are analyzed and compared. A new magnetic structure, which consists of hybrid materials with different permeability, is proposed to reduce the number of gaps and simplify the magnetic design. The structure is implemented for the two kinds of integrated inductors with either coupled or uncoupled windings. In section IV, a $3 \mathrm{MHz}$ WPT system is built, and the topologies of the class-E inverters are also applied for rectification. A detailed comparison (regarding efficiency, harmonic current and temperature rise) for the different integrated inductors is presented.

\section{Circuit Design}

As in Fig.1, the windings of the integrated inductor can be either coupled or uncoupled, thus the circuit design is different for the cases. If the windings are uncoupled, i.e., $k_{i n}=0$, the circuit design is the same as a single-switch class-E inverter and has been well studied in existing literature [6], [8]. Note that the current amplitude of the inductor windings is kept large to satisfy ZVS when the load resistance varies from an optimal value to infinity. Since the switches are driven by complementary signals, the inverter operates

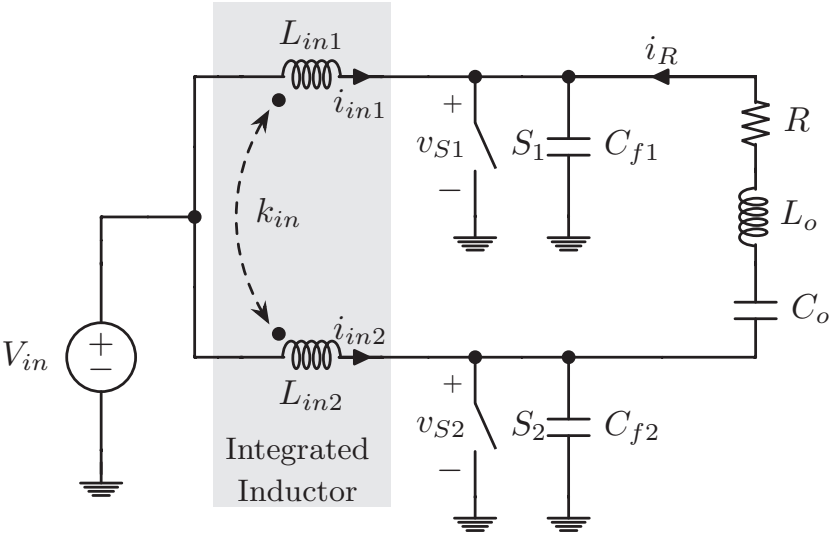

Fig. 1. Push-pull class-E inverter with an integrated inductor. The windings ( $L_{i n 1}$ and $L_{i n 2}$ ) can be either coupled or uncoupled.

in differential mode. Hence, the fundamental and odd-order harmonic currents circulate in the inverter, while the evenorder ones can pass through the DC source.

For the other case, i.e., $k_{i n} \neq 0$, the ripple current of DC source can be suppressed by coupling the windings. This topology has been proposed in [12], but its design criteria to achieve ZVS are still unknown. Therefore, in this section, the analysis focus on the inverter with coupled windings.

\section{A. Switch Voltage for Coupled Windings}

For the topology with coupled windings, the designed inductance for different order harmonics can be separated. The inductance for even-order harmonic currents is equal to the selfinductance of the windings. On the other hand, the inductance for fundamental and odd-order harmonic currents is equal to the leakage inductance. Therefore, it is an essential principle that increasing the self-inductance for ripple suppression and keeping a particular leakage inductance to satisfy ZVS. Hence, the ideal integrated inductor with coupling windings acts like a transformer with particular leakage inductance. Since the switching behavior is changed by the coupled windings, it requires a new design criterion to achieve ZVS as well as conventional class-E inverters. To simplify the analysis below, some assumptions are made as follows.

1) The switches have zero on-resistance and infinite offresistance. The switch $S_{1}$ is on for $0<\omega t \leq \pi$ and off for $\pi<\omega t \leq 2 \pi$. In reverse, $S_{2}$ is off for $0<\omega t \leq \pi$ and on for $\pi<\omega t \leq 2 \pi$. Hence, the switch voltages satisfy

$$
v_{s}(\omega t)=v_{s 1}(\omega t)=v_{s 2}(\omega t+\pi)
$$

2) The equivalent series resistance of passive components is ignored.

3) $Q_{L}$ is high enough to make the output current $i_{R}$ a purely sinusoidal wave expressed as

$$
i_{R}(\omega t)=I_{R} \cdot \sin (\omega t+\varphi)
$$

The $L_{o}$ and $C_{o}$ resonate at the operation frequency, i.e., $\omega=$ $1 / \sqrt{L_{o} C_{o}}$.

4) The mutual inductance and leakage inductance, i.e.,

$$
L_{c}=k_{i n} L_{i n}
$$




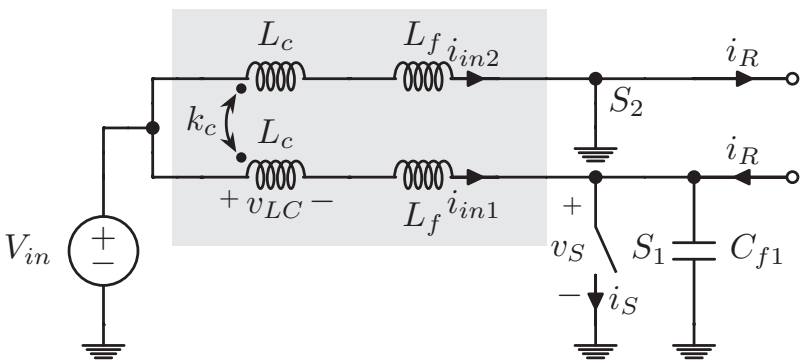

(a) The equivalent circuit with off-state $S_{1}$.

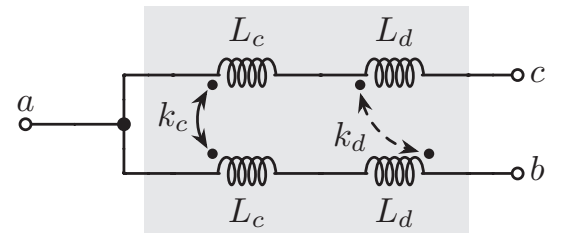

(b) The equivalent model of the integrated inductor with coupled windings.

Fig. 2. The equivalent circuit when $S_{1}$ is off for $\pi<\omega t \leq 2 \pi$. The coupling coefficient $k_{c}=1$. The value of $k_{d}$ depends on the magnetic structure, and $L_{f}=\left(1+k_{d}\right) L_{d}$.

$$
L_{f}=\left(1-k_{i n}\right) L_{i n}
$$

satisfy $L_{c} \gg L_{f}$. Thus, the winding current can be decomposed by a direct current and an alternating current as

$$
\begin{aligned}
& i_{i n 1}(\omega t)=I_{D C}+i_{L f}(\omega t) \\
& i_{i n 2}(\omega t)=I_{D C}-i_{L f}(\omega t)
\end{aligned}
$$

Since the circuit units are symmetrical, the winding currents satisfy

$$
i_{L f}(\omega t)=-i_{L f}(\omega t+\pi)
$$

which implies that there is no common-mode current if the windings are coupled and the self-inductance is large enough. The even-order harmonic currents can be eliminated theoretically.

Fig.2a illustrates the equivalent circuit of the inverter when $S_{1}$ is off. The $C_{f 2}$ is removed from the circuit since it is shorted by the on-state $S_{2}$. The integrated inductor is simply formed by the mutual inductance $L_{c}$ and the leakage inductance $L_{f}$. Usually, the equivalent model of the inductor can also be described by two coupled parts as in Fig.2b for satisfying energy conservation. The latter model can be transformed by using $L_{f}=\left(1+k_{d}\right) L_{d}$ for the analysis below.

The coupled windings act as a transform with particular leakage inductance because $L_{c} \gg L_{f}$. Therefore, when $S_{2}$ is shorted for $\pi<\omega t \leq 2 \pi$, the voltage across $L_{c}$ is

$$
v_{L c}(\omega t)=V_{i n}+\omega L_{f} \frac{d i_{L f}(\omega t)}{d \omega t} .
$$

From (7) and (8), the charging current of $C_{f 1}$ for $\pi<\omega t \leq 2 \pi$ satisfies

$$
\omega C_{f} \frac{d v_{S}(\omega t)}{d \omega t}=\frac{-1}{\omega L_{e}} \int_{\pi}^{\omega t} v_{S}\left(\omega t_{1}\right) d \omega t_{1}+I_{L \pi}+i_{R}(\omega t)
$$

which can be represented by a second-order differential form expressed as

$$
\frac{1}{q_{e}^{2}} \frac{d^{2} v_{S n}(\omega t)}{d \omega t^{2}}+v_{S n}(\omega t)-p_{e} \cdot \cos (\omega t+\varphi)=0
$$

The general solution of equation (10) is

$$
v_{S n}(\omega t)=\xi_{1} \cos \left(q_{e} \omega t\right)+\xi_{2} \sin \left(q_{e} \omega t\right)-\xi_{e} \cos (\omega t+\varphi)
$$

where $\xi_{e}=q_{e}^{2} p_{e} /\left(1-q_{e}^{2}\right), \xi_{1}$ and $\xi_{2}$ are the coefficients related to the circuit parameters of the inverter. Calculating the derivative of (11) as

$$
\frac{d v_{S n}(\omega t)}{d \omega t}=\xi_{2} \cos \left(q_{e} \omega t\right)-\xi_{1} \sin \left(q_{e} \omega t\right)+\xi_{e} \sin (\omega t+\varphi) \text {. }
$$

From equation (9) and (12) at $\omega t=\pi$, the initial conditions can be expressed by

$$
\begin{gathered}
v_{S n}(\pi)=0 \\
\left.\frac{d v_{S n}(\omega t)}{d \omega t}\right|_{\omega t=\pi}=q_{e}^{2} p_{\pi e}-q_{e}^{2} p_{e} \sin (\varphi)
\end{gathered}
$$

Solving equation (11) based on the initial conditions and resulting in the expressions of $\xi_{1}$ and $\xi_{2}$ given by

$$
\begin{aligned}
\xi_{1}= & -\xi_{e}\left[\cos \left(\pi q_{e}\right) \cos (\varphi)+\frac{1}{q_{e}} \sin \left(\pi q_{e}\right) \sin (\varphi)\right] \\
& -q_{e} \sin \left(\pi q_{e}\right) \cdot\left[p_{\pi e}-p_{e} \sin (\varphi)\right] \\
\xi_{2}= & -\xi_{e}\left[\sin \left(\pi q_{e}\right) \cos (\varphi)-\frac{1}{q_{e}} \cos \left(\pi q_{e}\right) \sin (\varphi)\right] \\
& +q_{e} \cos \left(\pi q_{e}\right) \cdot\left[p_{\pi e}-p_{e} \sin (\varphi)\right]
\end{aligned}
$$

To get the switch voltage for a particular value of $q_{e}$, it requires three constraint expressions for calculating the unknown state variables $\left(p_{e}, p_{\pi e}, \varphi\right)$. In this paper, the constraint conditions include a) Volt-second balance of windings; b) Energy conservation; c) Ohm's law for the fundamental voltage and current. The equations are deduced as follows.

1) According to the volt-second balance principle, the offstate switch voltage $v_{S n}$ defined in assumption 1) for $\pi<\omega t \leq$ $2 \pi$ satisfies

$$
2 \pi=\int_{\pi}^{2 \pi} v_{S n}\left(\omega t_{1}\right) d \omega t_{1}
$$

Substituting (11) into (16), resulting in

$$
\begin{aligned}
p_{\pi e}= & 2 \cdot \frac{\pi+\xi_{e} \sin (\varphi)}{1-\cos \left(\pi q_{e}\right)}+\frac{\xi_{e} \cos (\varphi) \sin \left(\pi q_{e}\right)}{q_{e}\left(1-\cos \left(\pi q_{e}\right)\right)} \\
& +\left(p_{e}-\frac{\xi_{e}}{q_{e}^{2}}\right) \sin (\varphi)
\end{aligned}
$$

2) As the input voltage is constant, the input energy $g_{\text {in }}$ per period is

$$
g_{i n}=\frac{2 \pi}{\omega} \cdot V_{i n} I_{D C}=\frac{2 \pi}{\omega} \cdot V_{i n} \cdot \frac{i_{i n 1}(\pi)+i_{i n 1}(2 \pi)}{2}
$$

From (5), (6), (7) and (12), getting

$$
\begin{aligned}
\beta_{I D C} & =\frac{2 I_{D C}}{V_{i n} \omega C_{f}} \\
& =q_{e}^{2} p_{\pi e}-q_{e}^{2} p_{e} \sin (\varphi)+\left.\frac{d v_{S n}(\omega t)}{d \omega t}\right|_{\omega t=2 \pi}
\end{aligned}
$$


The energy dissipation per period $g_{\text {out }}$ consists of the energy consumption of $R$ and the loss of $C_{f 1}$. It can be expressed as

$$
\frac{g_{\text {out }}}{V_{\text {in }}^{2} C_{f}}=\pi q_{e}^{2} p_{e}^{2} p_{r e}+\frac{1}{2} v_{S n}(2 \pi)^{2}
$$

Combining (18), (19) and (20), the equation for energy conservation is

$$
\pi \cdot \beta_{I D C}=\pi q_{e}^{2} p_{e}^{2} p_{r e}+\frac{1}{2} v_{S n}(2 \pi)^{2}
$$

3) According to the symmetry shown in (5),(6) and (7). The input current $i_{i n}$ can be normalized as

$$
\begin{aligned}
& \beta_{\text {in }}(\omega t)=\frac{i_{i n 1}(\omega t)}{V_{i n} \omega C_{f}} \\
& = \begin{cases}\beta_{I D C}-\beta_{i n}(\omega t+\pi) & 0<\omega t \leq \pi \\
\frac{d v_{S n}(\omega t)}{d \omega t}-q_{e}^{2} p_{e} \sin (\omega t+\varphi) & \pi<\omega t \leq 2 \pi\end{cases}
\end{aligned}
$$

From (9), the normalized switch current $i_{S}(\omega t)$ for $0<\omega t \leq$ $\pi$ is

$$
\beta_{S}(\omega t)=\frac{i_{S}(\omega t)}{V_{i n} \omega C_{f}}=\beta_{i n}(\omega t)-q_{e}^{2} p_{e} \sin (\omega t+\varphi)
$$

At the switching-on instant without ZVS condition, $C_{f 1}$ is discharged through $S_{1}$. According to charge conservation, the transient integral can be theoretically given by

$$
\int_{0}^{0+} i_{S}\left(\omega t_{1}\right) d \omega t_{1}=V_{i n} \omega C_{f} \cdot v_{S n}(2 \pi) .
$$

The fundamental current flowing through the switch can be decomposed into two quadrature components. Since the inductance $L_{c}$ only affects the common-mode currents, the third constraint condition can be written as

$$
\begin{array}{r}
\frac{\int_{0}^{\pi} \beta_{S}\left(\omega t_{1}\right) \cos \left(\omega t_{1}+\varphi\right) d \omega t_{1}+v_{S n}(2 \pi) \cos (\varphi)}{\int_{0}^{\pi} \beta_{S}\left(\omega t_{1}\right) \sin \left(\omega t_{1}+\varphi\right) d \omega t_{1}+v_{S n}(2 \pi) \sin (\varphi)} \\
=\frac{R}{2}\left(\omega C_{f}-\frac{1}{\omega L_{f}}\right)=\left(\frac{1}{q^{2}}-1\right) p_{r}
\end{array}
$$

As a result, the three state-variables $\left(p_{e}, p_{\pi e}, \varphi\right)$ can be numerically solved out from the constraint equations with particular circuit parameters $q_{e}$ and $p_{r e}$.

\section{B. Parameters for Satisfying ZVS and ZVDS Simultaneously}

The optimum condition of a class-E inverter is normally defined as satisfying ZVS and zero-voltage-derivative-switching (ZVDS) simultaneously. As the switching voltage and current are zero, the inverter can achieve minimum switching losses in practical systems. The optimum conditions can be expressed as

$$
\begin{gathered}
v_{S n}(2 \pi)=0 \\
\left.\frac{d v_{S n}(\omega t)}{d \omega t}\right|_{\omega t=2 \pi}=0
\end{gathered}
$$

Solving the equation set formed by (16), (21), (25), (26) and (27), the optimum $q$ and $p_{r}$ for the inverter with coupled windings are

$$
q_{o p t m 1}=1.659, \quad p_{\text {roptm } 1}=1.197 .
$$

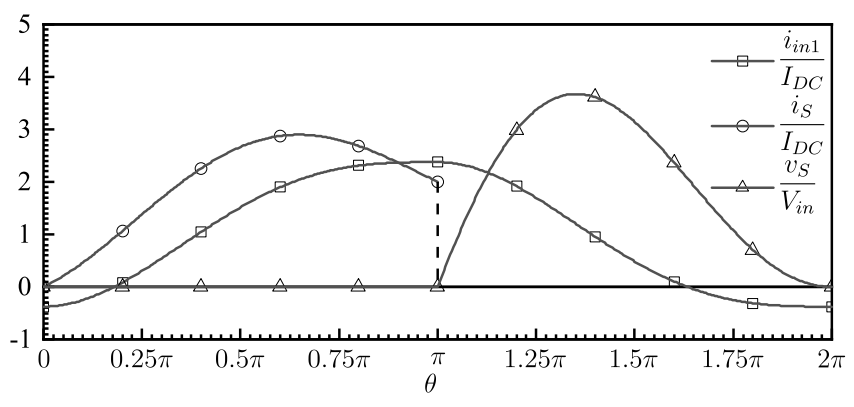

(a) Waveforms for coupled windings

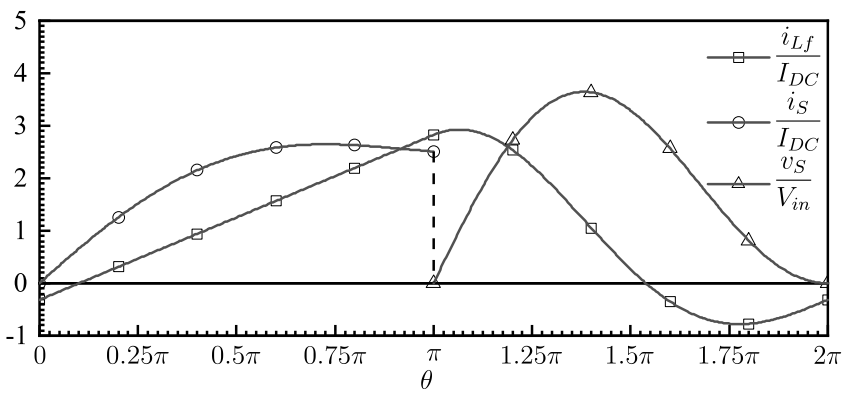

(b) Waveforms for uncoupled windings

Fig. 3. The normalized waveforms of class-E inverters satisfying both ZVS and ZVDS. The peak-to-peak of input current in sub-figure (a) is about $25.7 \%$ lower than that in (b), and the switching-off current is also decreased by $20.4 \%$.

In the definition $q=1 / \omega \sqrt{L_{f} C_{f}}$ and $p_{r}=R / \omega L_{f}$ for the inverter with coupled windings, $L_{f}$ equals to the inductance for the differential-mode current (i.e., fundamental and oddorder harmonic currents).

In contrast, for the inverter with uncoupled windings, the definitions should be changed to $q_{t r d}=1 / \omega \sqrt{L_{i n} C_{f}}$ and $p_{\text {rtrd }}=R / \omega L_{i n}$, where the inductance for the differentialmode current is $L_{i n}$.

The optimum $q_{t r d}$ and $p_{\text {rtrd }}$ can be calculated as a class$\mathrm{E}$ inverter with finite DC-feed inductance. According to the calculation in [7]. The optimum circuit parameters are

$$
q_{\text {optm } 2}=1.412, \quad p_{\text {roptm } 2}=1.364 .
$$

Note that, $L_{i n}$ is limited by the design criterion of the class-E inverter with finite DC-feed inductance. Therefore, using the uncoupled windings will not directly improve the suppression of odd-order harmonic currents. Contrarily, it may reduce the suppression since $q_{\text {optm } 2}$ is slightly lower than $q_{\text {optm } 1}$. As in Fig.3, there is no distinct difference between the switch voltages for the coupled and uncoupled windings, while the winding current amplitude is observably reduced by using the coupled windings.

\section{Parameters for Satisfying Only ZVS}

The selection of circuit parameters can be more flexible by relaxing the switching conditions to achieving only ZVS. Tab.I is solved by removing (27) from the equation set and presetting $q$ values. The waveforms for different cases are illustrated in Fig.4. It shows that the peak switch voltage decreases with a lower $q$ value, but the winding current amplitude at $q=1.45$ 
TABLE I

PARAMETER SETS FOR SATISFYING ZVS

\begin{tabular}{c|lccc}
\hline Cases & \multicolumn{1}{|c}{$q$} & $p_{r}$ & $p$ & $\varphi$ \\
\hline $\mathrm{a}$ & 1.45 & 2.341 & 0.675 & 0.114 \\
$\mathrm{~b}$ & 1.5 & 1.624 & 0.983 & 0.179 \\
$\mathrm{c}$ & 1.659 & 1.197 & 1.381 & 0.316 \\
$\mathrm{~d}$ & 1.8 & 1.151 & 1.491 & 0.415 \\
$\mathrm{e}$ & 1.95 & 1.191 & 1.515 & 0.514 \\
\hline
\end{tabular}

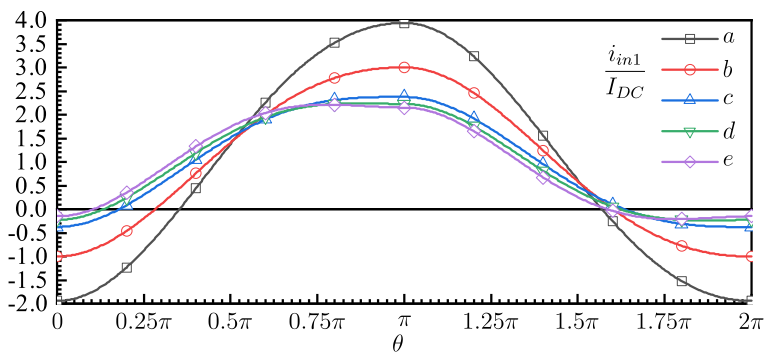

(a) Normalized winding current

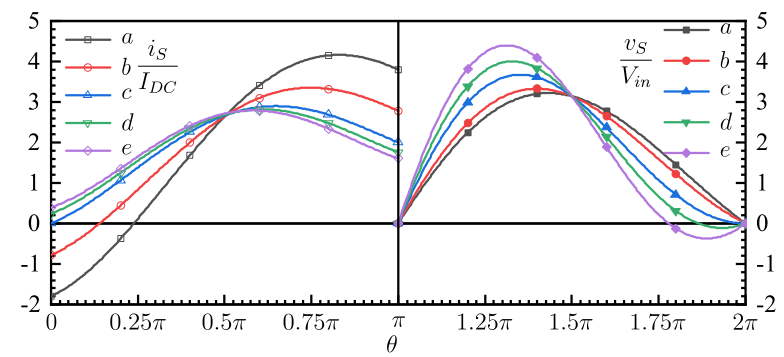

(b) Normalized switch current and voltage

Fig. 4. Voltages and currents of the inverter with coupled windings when varying value of $q$.

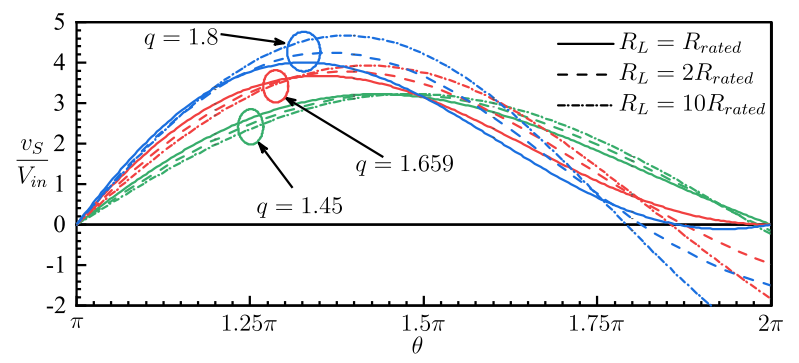

Fig. 5. Switch voltages for coupled windings with different $q$ and load resistance.

even increases to about 2 times that at $q=1.659$. In contrast, when $q>1.8$, the amplitude tend to be unchanged.

Fig.5 illustrates the switch voltages with different $q$ and $R$. The switch satisfies ZVS when $R>R_{\text {rated }}$. Note that switching with a conductive body-diode of MOSFET is regarded as ZVS. The peak switch voltage has a larger range of variation when $R$ varies with a higher $q$ value. On the other hand, the switch voltages at $q=1.45$ tend to be load-independent. Therefore, the value of $q$ affects the winding currents and switch voltages significantly.

For an actual inverter, the circuit parameters can be calculated by

$$
R=\frac{p^{2} \cdot p_{r}^{2} \cdot V_{i n}^{2}}{2 P_{\text {out }}}
$$

$$
\begin{gathered}
L_{f}=\frac{R}{p_{r} \cdot \omega} \\
C_{f}=\frac{1}{L_{f} \cdot \omega^{2}}
\end{gathered}
$$

where $P_{\text {out }}$ is the output power of the inverter, $V_{\text {in }}$ is the DC input voltage. The designed $R$ is based on the rated output, thus the ZVS can be satisfied when the load resistance varies from its rated value to infinity.

\section{Magnetic Design FOR InTEGRATEd InduCtors}

Magnetic integration is commonly implemented by combining multiple inductors of a converter. The inductor windings of the inverter after integrated can be either coupled or uncoupled. These different cases result in a significant change in the circuit design. As in Fig.1, the parallel capacitance $C_{f}$ resonates with the self-inductance $L_{i n}$ if the windings are uncoupled. In contrast, if the windings are coupled, the $C_{f}$ resonates with the leakage inductance $L_{f}$. In this paper, both two kinds of integrated inductors are built and compared. We define the resonance inductance as $L_{\text {decpl }}$ and $L_{c p l}$ to highlight the difference between the cases.

\section{A. Integrated inductor with uncoupled windings}

Designing the integrated inductor with uncoupled windings is basically the same as that for a class-E inverter with finite DC-feed inductance. The winding inductance $L_{\text {decpl }}$ can be expressed as

$$
\begin{gathered}
L_{\text {decpl }}=L_{\text {in }}=N^{2} \frac{\mu_{0} A_{e}}{l_{e}} \\
l_{e}=\frac{l_{\text {core }}}{\mu_{r}}+l_{\text {gap }}
\end{gathered}
$$

where $N$ is the number of turns, $\mu_{0}=4 \pi \cdot 10^{-7} \mathrm{H} / \mathrm{m}, A_{e}$ is the effective cross-sectional area of the magnetic core, $l_{\text {core }}$ is the effective magnetic path length of the core, $\mu_{r}$ is the relative permeability of the core, $l_{\text {gap }}$ is the gap length, $l_{e}$ is the effective magnetic path length of $L_{\text {decpl }}$.

Fig.6 illustrates the magnetic integration for the uncoupled windings. The windings share the central column after integration. The even-symmetric common-mode fluxes are unchanged in the central column. In contrast, the odd-symmetric differential-mode ones are canceled. Therefore, the core loss can be slightly reduced by suppressing the flux through the shared column.

For size reduction, the integrated method can also reduce $A_{e}$ of the central column based on the same losses of individual inductors.

\section{$B$. Integrated inductor with coupled windings}

As mentioned in subsection II.A, the integrated inductor with coupled windings acts like a transformer with designed leakage-inductance $L_{f}$ and mutual-inductance $L_{c}$. The inductance for the even-order harmonic currents is $L_{f}+L_{c}$, while the inductance for the fundamental and odd-order harmonic currents is $L_{f}$. Hence, the values of $L_{c}$ and $L_{f}$ can be designed separately. 


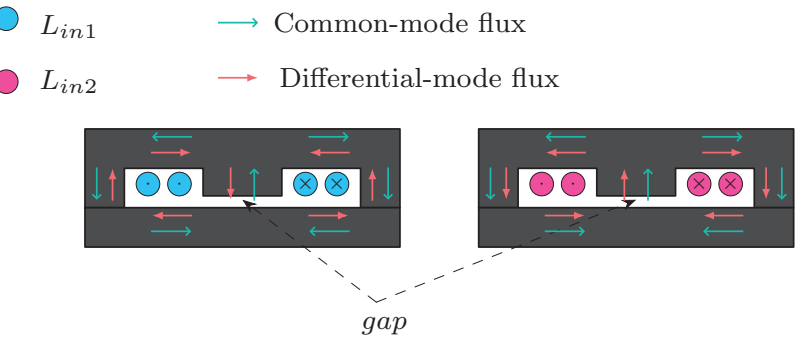

(a) Individual inductors

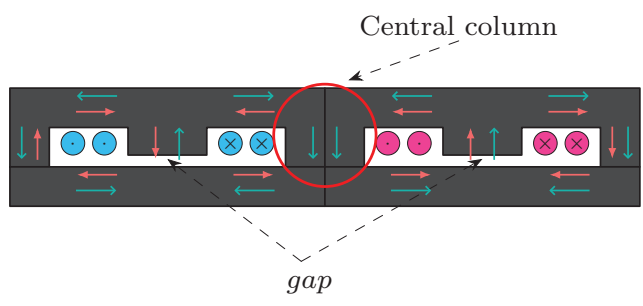

(b) Integrated inductor with uncoupled windings

Fig. 6. Magnetic integration for uncoupled windings. The differential-mode flux through the central column is canceled by combining the individual inductors.

Fig.7a is an "E-E" type magnetic structure for building an integrated inductor with two coupled windings. Three gaps are set avoid core saturation and adjusting the inductance. The common-mode flux, which is excited by the DC bias (defined in equation (5)) and the even-order harmonic currents, flows through the gaps of side-columns and bypasses the central gap. In contrast, the differential-mode flux, which is excited by the fundamental and odd-order harmonic currents, flows through all the three gaps. The suppression of even-order harmonic currents can be improved by reducing $l_{\text {gapd }}$, but the DC bias of inverter may cause saturation of the magnetic cores. Therefore, the gaps should be precisely set to suppress the harmonic

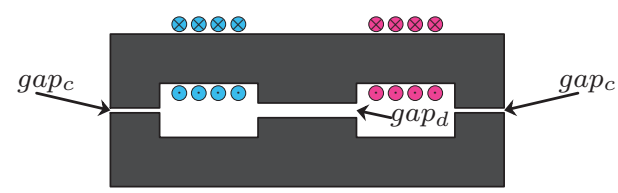

(a) Magnetic structure with 3 gaps (earlier work)
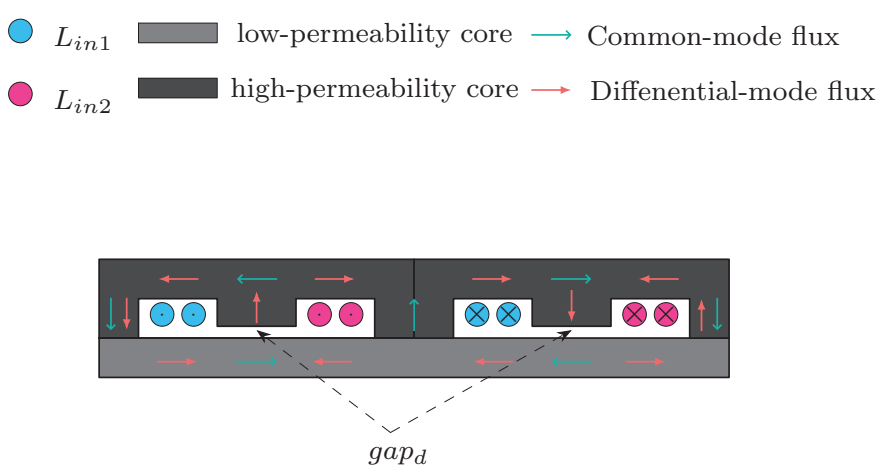

(b) Magnetic structure with hybrid cores(this paper)

Fig. 7. Magnetic structures for the integrated inductor with coupled windings. currents and prevent a significant increase in inductor loss.

As illustrated in Fig.7b, a new magnetic structure formed by hybrid materials is proposed to reduce the number of gaps and simplify the magnetic design. The low-permeability material is introduced to avoid core saturation without using gaps on the side-columns, while the high-permeability material benefits size reduction and makes sure $L_{c}$ is large enough to suppress the common-mode currents. Therefore, the $\operatorname{gap}_{c}$ is removed from the new structure, and the central gap is adjusted to get a preferred $L_{f}$. The inductance for common-mode and differential-mode harmonic currents can be respectively expressed as

$$
\begin{gathered}
L_{c}=N^{2} \frac{\mu_{0} A_{e}}{l_{e c}} \\
l_{e c} \approx \frac{l_{\text {coreh }}}{\mu_{r h}}+\frac{l_{\text {coreh }}}{\mu_{r l}}
\end{gathered}
$$

and

$$
\begin{gathered}
L_{c p l}=L_{f}=N^{2} \frac{\mu_{0} A_{e}}{l_{e f}} \\
l_{\text {ef }}=\frac{l_{\text {coreh }}}{\mu_{r h}}+\frac{l_{\text {corel }}}{\mu_{r l}}+l_{\text {gapd }}
\end{gathered}
$$

where $l_{\text {gapc }}$ and $l_{\text {gapd }}$ are the length of $\operatorname{gap}_{d}$ and $\operatorname{gap}_{c}$, respectively. $l_{e f}$ and $l_{e c}$ are the effective magnetic path length of $L_{c}$ and $L_{f} . l_{\text {coreh }}$ and $l_{\text {corel }}$ are the effective magnetic path length of the high-permeability core and the low-permeability core. $A_{e}$ is the effective cross-sectional area. Note that, the defined variables are based on one "E-I" type core.

Since $l_{e f} \gg l_{e c}$, the value of $L_{c}$ is much higher than $L_{f}$. Hence, the integrated inductor with coupled windings can achieve the suppression of even-order harmonic currents without using a filter.

Besides, since the magnetic cores are arranged next to each other, the differential-mode fluxes through the central column are also canceled. However, due to the higher field density bias caused by DC bias, the total core loss is still higher than that of the integrated inductor with uncoupled windings.

\section{Qualitative analysis for core losses}

Steinmetz empirical equation and its improved forms are usually applied to calculate the core-losses of magnetic components [14], [25]-[27]. The estimated core loss $P_{\text {core }}$ under sinusoidal flux density is given by

$$
P_{\text {core }}=\gamma f^{\alpha} B_{m}^{\beta} \cdot V_{\text {core }}
$$

where $\gamma, \alpha, \beta$ are the coefficients extracted from the material data sheets of magnetic cores, $V_{\text {core }}$ is the core volume, $B_{m}$ is the amplitude of excitation magnetic density. The prime part of $B_{m}$ caused by the fundamental harmonic of switch voltage can be approximately calculated by

$$
B_{m 1}=\frac{p \cdot p_{r} \cdot 2 V_{i n}}{N A_{e} \cdot \omega}
$$

where $N$ is the turns of each winding, $A_{e}$ is the area of the core section. According to Fourier series of the switch voltage in Fig.3a, the amplitude of the second-order harmonic voltage is about 0.54 times the fundamental harmonic voltage. Hence, 


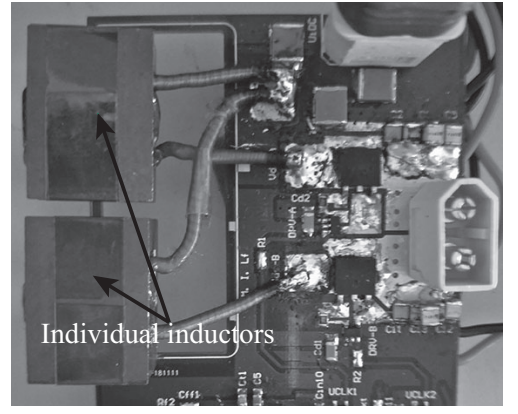

Fig. 8. Individual inductors for verifying loss reduction of the central column after magnetic integration. The output terminal is opened directly.

the flux density is non-sinusoidal, the material data sheets and Steinmetz equation cannot be used for calculating the core losses of integrated inductors.

Due to the non-sine excitation, estimating or measuring the losses of the integrated inductor is difficult to get accurate results. A more accurate method needs to be investigated in future works. To verify the effect of magnetic integration, a more feasible method is measuring and comparing the losses for different magnetic designs. As in Fig.8, two individual inductors $(0.67 \mu \mathrm{H})$ using "E-E" type cores (EQ25/5.6/18, PC200 material) are applied in a class-E inverter. The openload loss is about $11.6 \mathrm{~W}$ (at $3 \mathrm{MHz}$ ). Moving and pressing the two inductors together directly when measuring the open-load loss. The measurement is repeated continuously, and it shows that the open-load loss always instantly drops by about $0.2 \mathrm{~W}$ when the inductors are pressed together. There is no distinct change when measuring the system efficiency since the loss reduction is too small.

Generally, the optimization of a gaped inductor is a multiobjective problem, which relates to winding turns, core material, fringe-effect around gaps and so on. The losses of the integrated inductor are highly dependent on a particular design. Since there is no distinct difference in system features when the individual inductors are integrated together without coupling the windings, the integrated inductor with uncoupled windings can also represent the individual inductors. In this paper, therefore, we use the proposed magnetic structure to build the two kinds of integrated inductors for a fair comparison based on the same conditions. As illustrated in Fig.9, there are two high-permeability cores (EQ25/5.6/18) of PC200 material placed on a low-permeability core $(4.1 \mathrm{~mm}$ thickness plate) of $4 \mathrm{~F} 1$ material. The detailed comparison is presented below.

\section{Megahertz WPT Prototype with Class-E INVERTERS AND RECTIFIERS}

Several inverters and rectifiers with different integrated inductors are built to verify the analysis above. As illustrated in Fig.10, the WPT system consists of three parts, i.e., the class-E inverter, the magnetic resonant tank, and the class-E rectifier. Since class-E inverters can also operate for rectification, we use the same topology for rectifiers but replace the MOSFETs by diodes. The design criteria for inverters is also applied for the rectifiers.

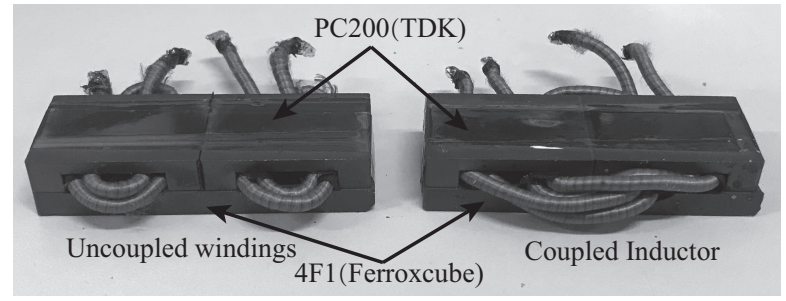

Fig. 9. Magnetic structure used for integrated inductors. For a fair comparison, we use the same cores for both kinds of integrated inductor with coupled windings and uncoupled windings.

\section{A. Magnetic Resonant Tank of WPT system}

The magnetic resonant tank consists of three resonant loops of which parameters meet

$$
\frac{1}{\omega^{2}}=L_{1} C_{1}=L_{2} C_{2 e q}=L_{3} C_{3} \text {. }
$$

where $C_{2 e q}=C_{1} C_{2} /\left(C_{1}+C_{2}\right)$. The first resonant loop acts as an output filter of the class-E inverter, and the third loop acts as an input filter of the class-E rectifier. Therefore, the topology is well simplified. For a better comparison, we use the same parameters for the inverter and rectifier. Since they are symmetrical, the voltage gain and the load resistance of the system can be approximately given by

$$
\begin{gathered}
\frac{V_{\text {out }}}{V_{\text {in }}} \approx \frac{k_{23} \sqrt{L_{3}}}{k_{12} \sqrt{L_{1}}} \\
R_{L}=\frac{V_{\text {out }}^{2}}{P_{\text {out }}}
\end{gathered}
$$

where $k_{23}$ are the coupling coefficient between $L_{2}$ and $L_{3}$. $k_{12}=\sqrt{L_{1} /\left(L_{1}+L_{2}\right)}$ is defined as the equivalent coupling coefficient. As in Fig.11, the WPT system is designed to achieve a DC-DC converter ( $48 \mathrm{~V}$ to $48 \mathrm{~V}$ ) with rated output power about $300 \mathrm{~W}$. The value of $k_{23}$, which is about 0.3 in this paper, is limited by the transfer distance and the coil diameters. Hence, the values of $L_{1}, L_{2}$ and $L_{3}$ are adjusted to realize the expected voltage gain as in Tab.II.

\section{B. Experiment Setup for Inverters and Rectifiers}

1) Circuit Design and Component Selection: The parameters of the class-E inverter and rectifier with uncoupled windings are calculated based on the optimal $q_{t r d}$ and $p_{\text {rtrd }}$ as in equation (29). The circuit design is the same as a class-E inverter with finite DC-feed inductance [7].

The circuit parameters of inverters and rectifiers with coupled windings are calculated by (30), (31) and (32). The variables in these equations are obtained by solving the equation set discussed in subsection II.C.

Note that, the parameters are calculated based on the rated power of $360 \mathrm{~W}$, and realize an actual output power of about $300 \mathrm{~W}$ of the receiver considering the system losses. The operation frequency is $3 \mathrm{MHz}$ according to the optimal frequency range described in material data sheets. The applied values of $C_{f}$ are lower than the calculated values due to the nonlinear parasitic capacitance of switches (about $130 \mathrm{pF}$ for MOSFETs, $30 \mathrm{pF}$ for diodes) . 


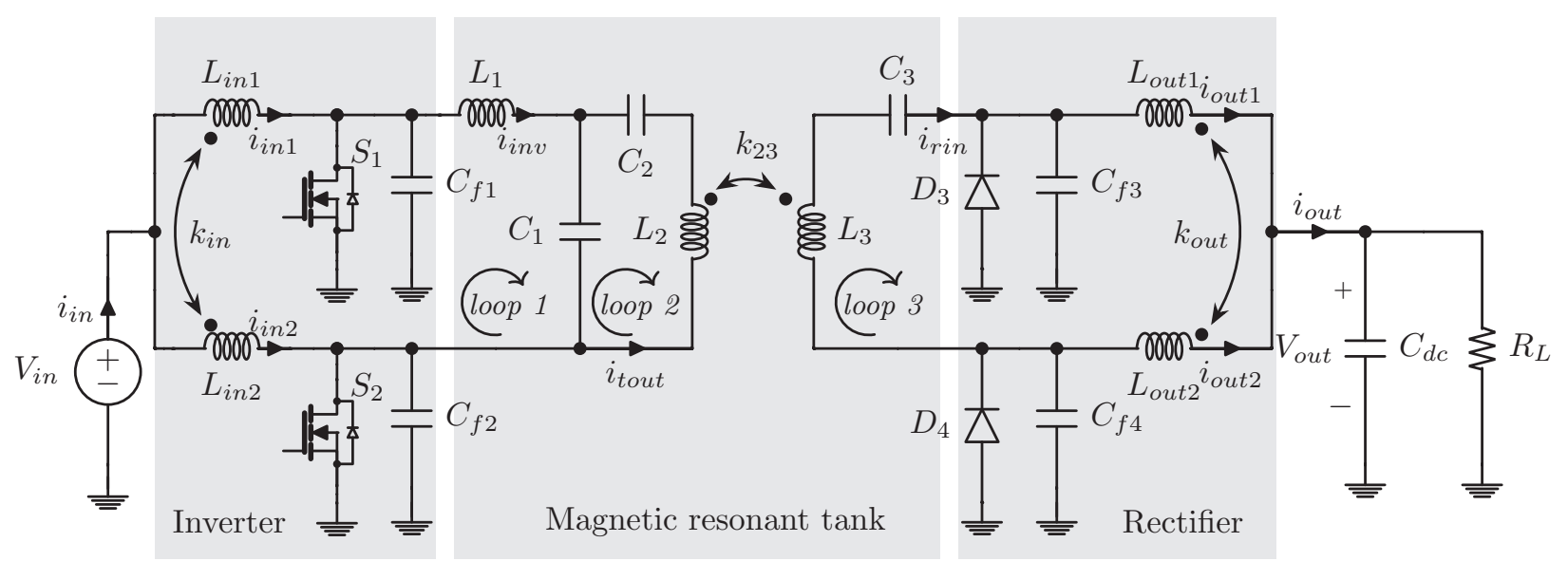

Fig. 10. Topology of the WPT prototype. The class-E rectifier has the similar topology as well as the inverter, but it uses diodes as switching devices. When the inverter/rectifier consists of the integrated with uncoupled windings, the coupling coefficient $k_{i n}=0$.

TABLE II

PARAMETERS OF WPT PROTOTYPE

\begin{tabular}{|c|c|c|c|c|c|c|c|c|c|}
\hline \multirow{2}{*}{\multicolumn{3}{|c|}{ Magnetic resonant tank }} & \multicolumn{5}{|c|}{ Coupled windings } & \multirow{2}{*}{\multicolumn{2}{|c|}{$\begin{array}{c}\text { Uncoupled windings } \\
q=1.412\end{array}$}} \\
\hline & & & \multirow{2}{*}{$P_{\text {rated }}=360 \mathrm{~W}, V_{\text {in }}=48 \mathrm{~V}$} & \multicolumn{2}{|c|}{$q=1.659$} & \multicolumn{2}{|c|}{$q=1.53$} & & \\
\hline & alc. & Meas. ${ }^{a}$ & & Calc. & Meas. & Calc. & Meas. & Calc. & Meas. \\
\hline & & 2. & $L_{c p l}, L_{\text {decpl }}(\mu \mathrm{H})$ of inverter & 0775 & 0.78 & 0600 & 0.59 & 0,679 & $0.65,0.68$ \\
\hline & & &,$L_{d \epsilon}$ & & 0.74 & 0.0 & 0.60 & 0.019 & $0.64,0.66$ \\
\hline$L_{2}$ & 9. & 10. & $R_{r}$ & 17.48 & - & 16.50 & - & 17.45 & - \\
\hline$C_{2}$ & 0.302 & 0 . & $C_{f 1}$ & 1310 & 1.200 & 20 & 1.860 & 078 & 1.940 \\
\hline$L_{3}(\mu \mathrm{H})$ & 7.6 & 8.646 & $C_{f 3}$, & 1.319 & 1.300 & 2.002 & 2.000 & 2.019 & 2.047 \\
\hline$C_{3}(\mathrm{nF})$ & 0.367 & 0.326 & Switches & & $\overline{\mathrm{Y} 36 \mathrm{~N}}$ & $\left(S_{1}\right.$ & , FF & $\overline{0 \mathrm{UP} 20}$ & $\overline{\left.D_{3}, D_{4}\right)}$ \\
\hline
\end{tabular}

${ }^{a}$ Extracted from measured data of the resonant loops by an impedance analyzer (WK6500B).

${ }^{\mathrm{b}}$ The values of applied $C_{f}$ in the table are given by the nominal values of capacitors applied on PCB.

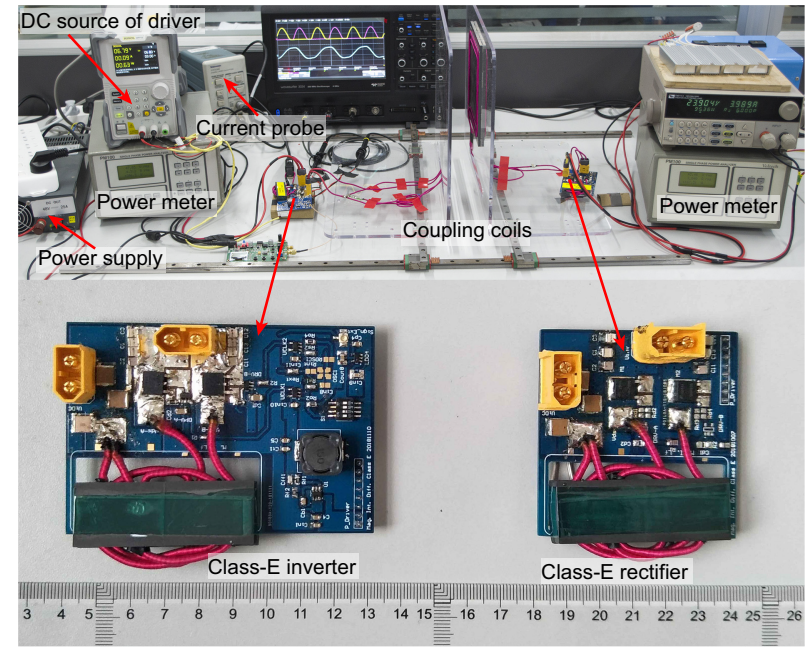

Fig. 11. Experiment setup of the WPT system. The coupling coils consist of two square coils which are $15 \mathrm{~cm} \times 15 \mathrm{~cm}$. The transfer distance is fixed at $4 \mathrm{~cm}$ which makes the coupling coefficient about 0.3 . The inductor $L_{1}$ formed by an 8 -shaped coil is integrated at the transmitting coil.

Since the switching frequency is up to megahertz, the selection of the switch components is critical for the system efficiency. To reduce rectification losses, the forward voltage and junction capacitance of the diodes should be as low as possible. In this paper, ultrafast diodes (FFD10UP20S) are applied for the class-E rectifiers.
For the class-E inverters, since the duty cycle is fixed at $50 \%$, the requirement for rise time and fall time of switches is relaxed comparing to PWM mode converters of which duty cycle can substantially shift from $50 \%$. The selection of the switches of class-E inverters is related to various specifications, such as the gate charge, on-resistance, withstand voltage, rise time and fall time. The driving losses and frequency are limited by the gate charge. The power dissipation of the MOSFET package is highly dependent on the on-resistance, rise time and fall time. In addition, the parallel capacitor of class-E inverters should consider the non-linear drain-source capacitance $C_{D S}$ of MOSFET. Thus, the highest switching frequency of a class-E inverter is essentially limited by the value of $C_{D S}$. In this paper, the IXFY36N20X3 MOSFET, which has a relatively low parasitic capacitance and switching time, is selected for the class-E inverters operating at $3 \mathrm{MHz}$.

2) Integrated Inductors: The integrated inductors which were built in section III.C are applied in the prototype. For a class-E inverter with coupled windings, the resonance inductance $L_{c p l}$ is half of the measured value between terminal $b$ and $c$ of the integrated inductor illustrated in Fig.2b.

Likewise, for a class-E inverter with uncoupled windings, the resonance inductance $L_{\text {decpl }}$ can be measured directly. Hence, there are two values of $L_{c p l}$ or four values of $L_{d e c p l}$ for each group of one inverter and one rectifier as in Tab.II.

Besides, an optimized integrated inductor with coupled 

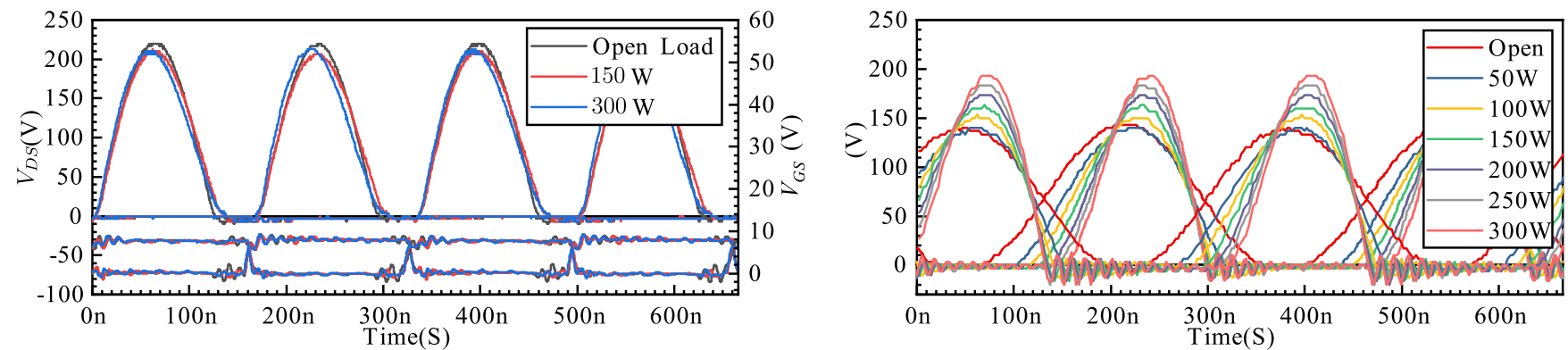

(a) $q=1.659$, coupled windings.
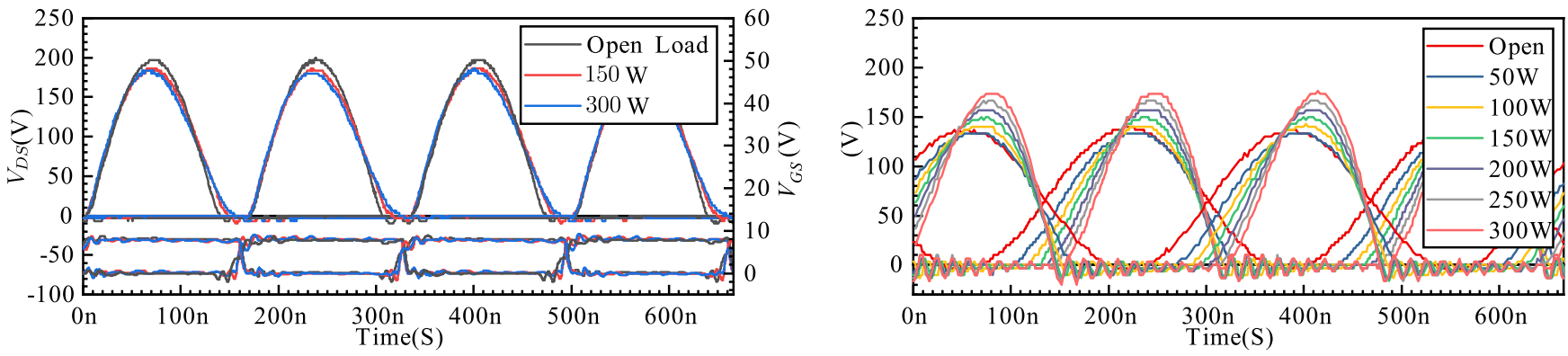

(b) $q=1.53$, coupled windings.
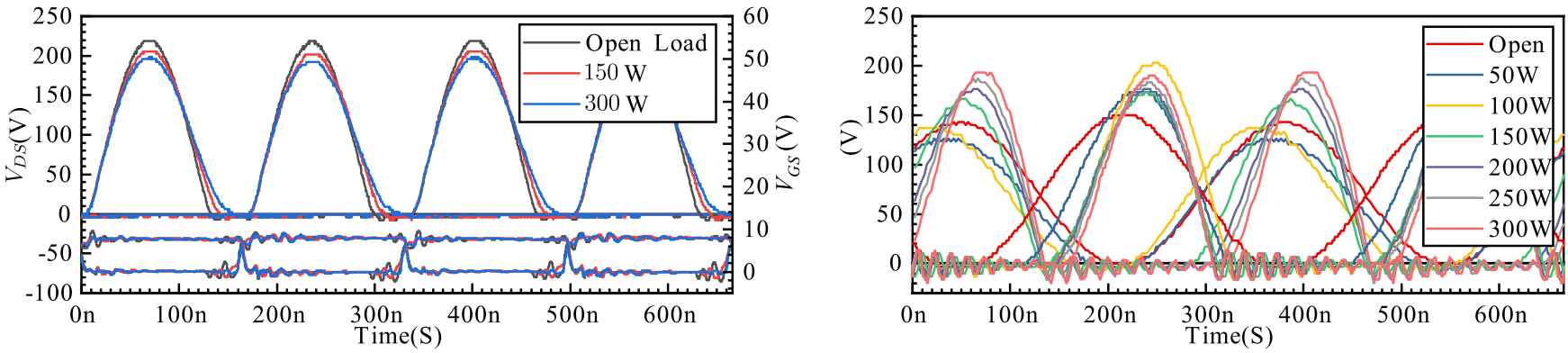

(c) $q=1.412$, uncoupled windings.

Fig. 12. Measure voltages of inverters and rectifiers. Left: drain-source voltages of MOSFETs of inverters. Right: reverse voltages of diodes of rectifiers.

windings is also implemented for the comparison of magnetic losses with different core size. The inductance of the optimized inductor is kept the same as that with $q=1.659$ in Tab.II, while the high-permeability cores (PC200, EQ25/5.6/18) are replaced by four pieces of smaller cores (PC200, ER23/5/13). The $A_{e}$ is increased from $93.51 \mathrm{~mm}^{2} \times 2$ to $50.3 \mathrm{~mm}^{2} \times 4$, i.e., by $7.6 \%$.

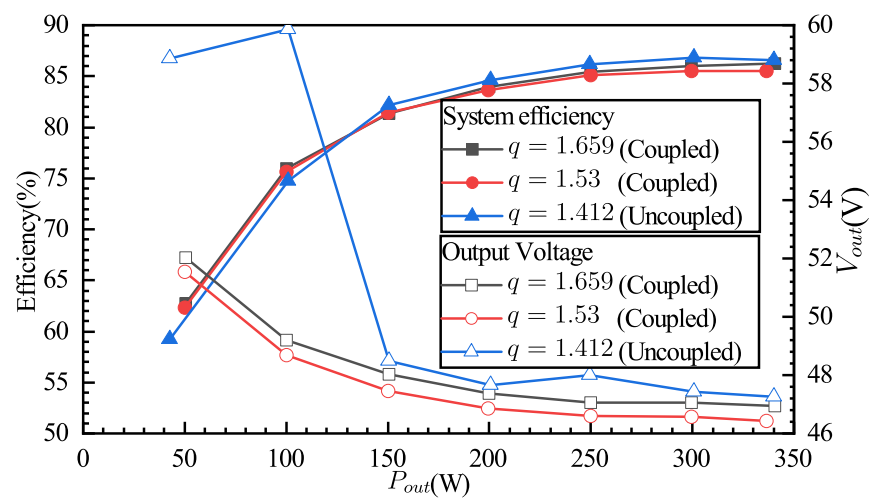

Fig. 13. Measured efficiency and output voltage with varying output power.

\section{Measurement}

1) Switch Voltage: Fig.12 illustrates the measured voltages over the output power range from zero to $300 \mathrm{~W}$. At the output power of $300 \mathrm{~W}$, the input power of the inverters is about 350 $\mathrm{W}$, which is closed to the rated value. Due to the nonlinear parasitic capacitance of MOSFETs and diodes, the measured peak voltages are higher than the theoretical values above.

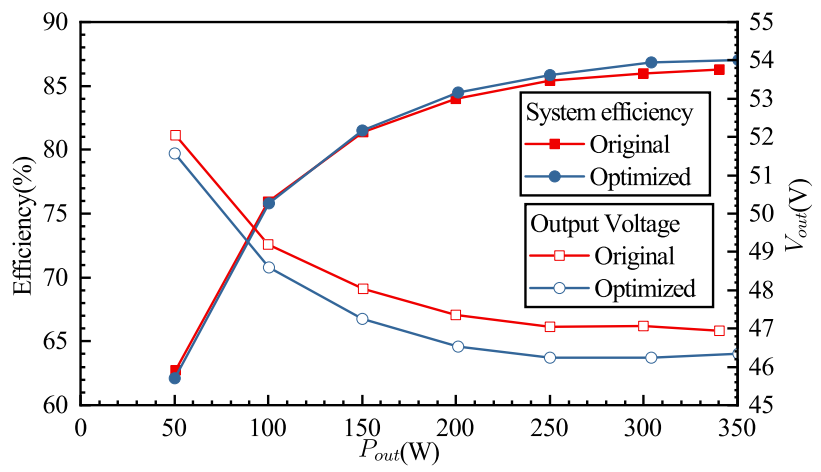

Fig. 14. Efficiency and output voltage of the prototype with the optimized integrated inductor $(q=1.659)$. 
As shown in the left sub figures, the ZVS is maintained over the entire load range without using closed-loop control. Comparing Fig.12a and Fig.12c, when the values of $q$ equal the optimum ones in (28) and (29), the voltage waveforms are similar despite whether the windings are coupled or uncoupled. In contrast, the voltage waveforms have lower peak values when $q=1.53$. Therefore, a lower value of $q$ helps reduce the required maximum $V_{D S}$ of the MOSFETs selected.

For the rectifiers, according to the basic circuit analysis of the magnetic resonant tank, the input and output currents, i.e., $i_{\text {inv }}$ and $i_{\text {rin }}$ have the same initial phase $\varphi_{r}$. When the system operates at the rated load, the phase of $i_{\text {rin }}$ shifted from the switching phase of $D_{3}$ meets $\varphi_{r}=\varphi_{3}+\pi-\varphi$ for rectification. Thus, the switching phases of the class-E rectifiers satisfy

$$
\varphi_{3}=2 \varphi, \quad \varphi_{4}=\pi+2 \varphi,
$$

where $\varphi_{3}$ and $\varphi_{4}$ are the initial switching phases of $D_{3}$ and $D_{4}$ shifted from the driving phase of $S_{1}$. The waveforms of rectifiers and inverters are supposed to be symmetrical when MOSFETs are applied for rectification. However, since the diodes are used for the rectifiers in the prototype, the duty cycle is changed adaptively when the load varies.

As in Fig.12c, due to the slight difference in the inductance of the uncoupled windings, the diode voltages show large unbalance at $50 \mathrm{~W}$ and $100 \mathrm{~W}$. The unbalance in the voltages results in an efficiency drop. In contrast, as in Fig.12a and Fig.12b, the diode voltages are balanced over the entire load range. Therefore, the issue of unbalanced voltages no longer exists when the windings are coupled.

The experiment results show that the class-E rectifiers present similar voltage waveforms no matter the windings are coupled or uncoupled. However, it is worth noting that the analytic models of the class-E rectifier with coupled windings are still unclear because the analysis of the inverter cannot be applied for the rectifier when both of diodes are in off-state.

2) Efficiency and Output Voltage: Fig.13 shows the system efficiency and output voltage over the output power range. The driving losses (about $0.7 \mathrm{~W}$ ) are not considered. The output voltage of the rectifier with uncoupled windings varies shapely when lightly loaded, while that with coupled windings are more stable. The peak efficiency of the system with uncoupled windings $(86.8 \%$ at $300 \mathrm{~W})$ is slightly higher than that with coupled windings $(86.3 \%$ at $340 \mathrm{~W})$ by about $0.5 \%$. When the output power is higher than $300 \mathrm{~W}$, the ZVS tends to be lost, and the efficiency will decrease, eventually. As in Fig.14, the reduced efficiency can be made up by enlarging the volume of the cores of the integrated inductor with coupled windings. Considering the existing magnetic cores are not optimized for the integrated inductor with coupled windings, there are chances to improve the efficiency in the future works further.

Fig.15 illustrates the steady-state thermal images of the circuit boards. Cooling fans are applied but without heatsink. The inverters and rectifiers have similar thermal characteristics. The temperature rise of the integrated inductor with coupled windings is apparently higher than that with uncoupled windings. In contrast, the diode temperature of the rectifiers with coupled windings is lower. As a result, coupling the windings will increase the core losses while decrease the switch losses at the same conditions.

When the operation frequency is up to megahertz, a small difference in time-delay between the current probe and the voltage probe will result in a non-ignorable phase shift, thus

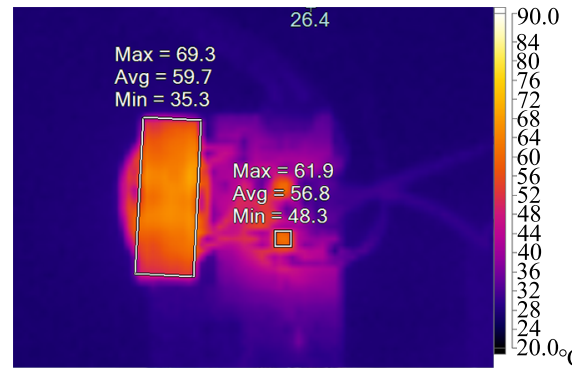

(a) Inverter with coupled windings

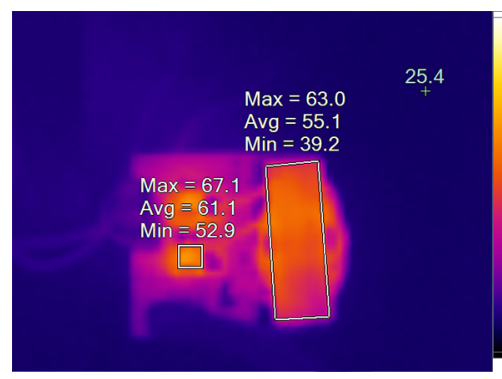

(d) Rectifier with coupled windings

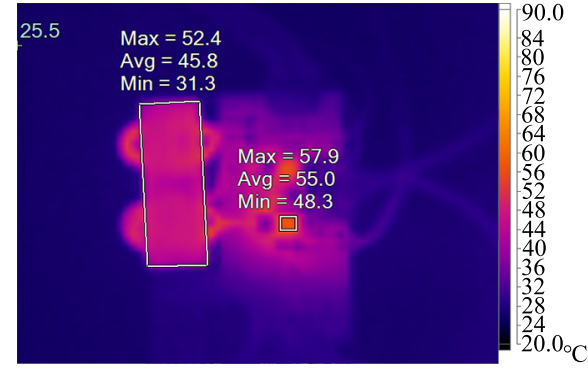

(b) Inverter with uncoupled windings

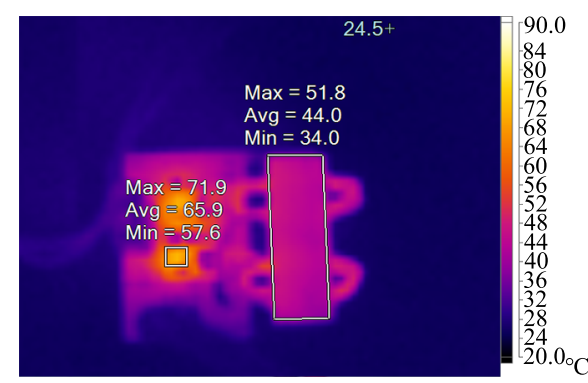

(e) Rectifier with uncoupled windings

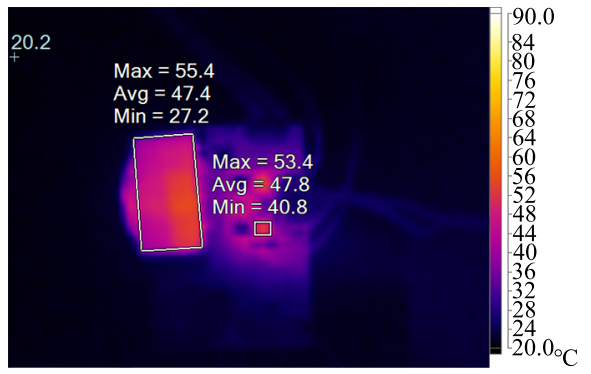

(c) Optimized Inverter with coupled windings

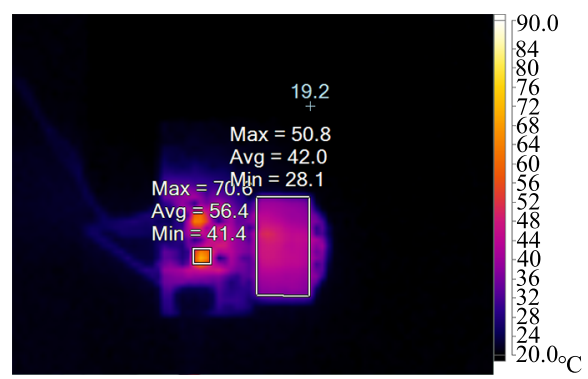

(f) Optimized Rectifier with coupled windings

Fig. 15. Thermal steady-state image of circuit broad of inverters and rectifiers at $300 \mathrm{~W}$ output. The system efficiency at $300 \mathrm{~W}$ is $85.97 \%$ for coupled windings, and $86.80 \%$ for uncoupled windings, respectively. By enlarging the core size of the integrated inductor with coupled windings, the system efficiency reaches $87.1 \%$ at $350 \mathrm{~W}$ output.The average temperature rise of magnetic cores is reduced by about $6^{\circ} \mathrm{C}$. 
TABLE III

ESTIMATED EFFICIENCY OF CLASS-E INVERTERS AND RECTIFIERS

\begin{tabular}{l|l|l|l|l|l|l}
\hline & $P_{\text {in }}$ & $P_{\text {out }}$ & $P_{\text {loop } 1}(406.87 \mathrm{~m} \Omega)$ & $P_{\text {loop } 2}(1.032 \Omega)$ & $P_{\text {loop } 3}(553.79 \mathrm{~m} \Omega)$ & $\eta_{\text {inv }}, \eta_{\text {rec }}$ \\
\hline Coupled windings $(q=1.659)$ & $348.6 \mathrm{~W}$ & $299.7 \mathrm{~W}$ & $3.42 \mathrm{~W}$ & $4.81 \mathrm{~W}$ & $4.27 \mathrm{~W}$ & $94.5 \%$ \\
\hline Uncoupled windings $(q=1.412)$ & $346.3 \mathrm{~W}$ & $300.6 \mathrm{~W}$ & $3.72 \mathrm{~W}$ & $4.73 \mathrm{~W}$ & $4.65 \mathrm{~W}$ & $95.1 \%$ \\
\hline Coupled windings $(o p t i m i z e d)(q=1.659)$ & $402.6 \mathrm{~W}$ & $350.6 \mathrm{~W}$ & $4.62 \mathrm{~W}$ & $4.85 \mathrm{~W}$ & $5.49 \mathrm{~W}$ & $95.2 \%$ \\
\hline
\end{tabular}

the integral of instantaneous power will be inaccurate. Consequently, measuring the inverter/rectifier efficiency or breaking down the total losses of the circuit broad is quite difficult.

To estimate the efficiency of the class- $E$ inverters and rectifiers, we assume that the inversion and rectification have the same efficiency, i.e., $\eta_{i n v}=\eta_{r e c}$ because they use the similar topology, integrated inductor and component package, except the switch types (MOSFETs for inverters, diodes for rectifiers). The thermal images also show that the inverters and rectifiers have similar temperature rise at $300 \mathrm{~W}$. In addition, the ESRs of the resonant loops of the magnetic resonant tank are almost constant since the core losses of the coupling coils are negligible. The total loss of magnetic resonant tank can be calculated according to the measured loop currents and ESRs (at $3 \mathrm{MHz}$ ).

The total loss of the magnetic resonant tank $P_{m a g}$ can be expressed by

$$
P_{\text {mag }}=P_{\text {in }} \cdot \eta_{i n v}-P_{\text {out }} / \eta_{\text {rec }}
$$

where $P_{\text {in }}$ and $P_{\text {out }}$ are the input and output power of the WPT system. $\eta_{i n v}, \eta_{r e c}$ is the efficiency of inverter and rectifier respectively.

Tab.III shows the estimated losses of the resonant loops and the efficiency of the class-E inverter/rectifier at the output

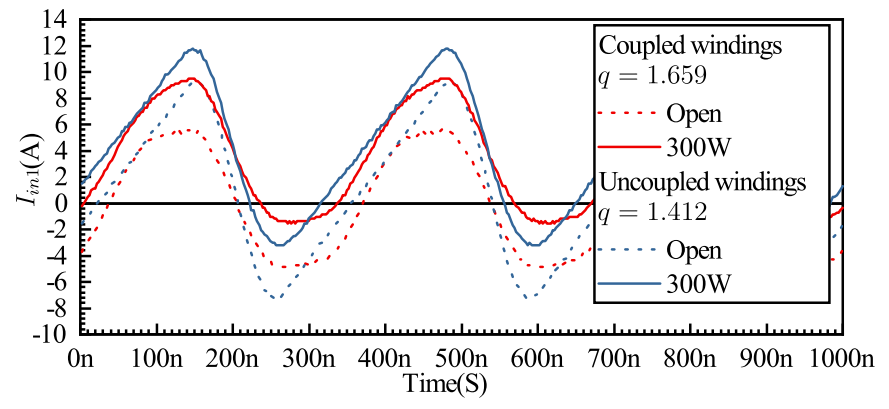

(a) Measured $i_{i n 1}$

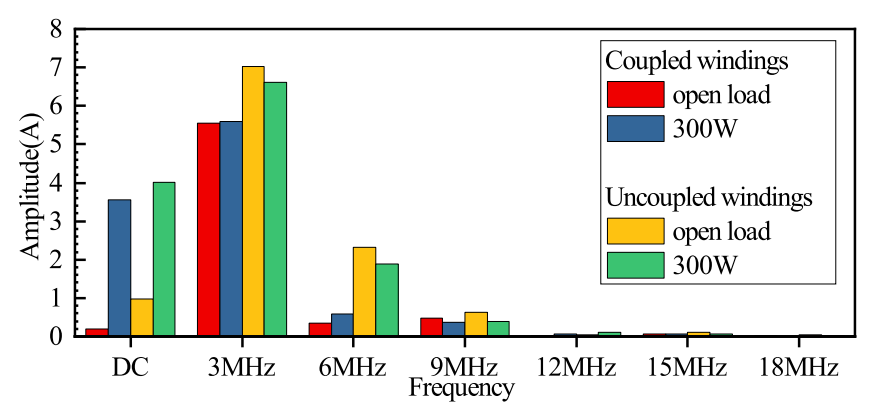

(b) FFT results for $i_{i n 1}$

Fig. 16. Measured winding currents $\left(i_{i n 1}\right)$. power of $300 \mathrm{~W}$. Assuming $\eta_{i n v}=\eta_{r e c}$, resulting in

$$
\begin{gathered}
\eta_{\text {inv }}=\eta_{\text {rec }}=\frac{P_{\text {mag }}+\sqrt{P_{\text {mag }}^{2}+4 P_{\text {in }} P_{\text {out }}}}{2 P_{\text {in }}} \\
P_{\text {mag }}=P_{\text {loop } 1}+P_{\text {loop } 2}+P_{\text {loop } 3}
\end{gathered}
$$

where $P_{\text {loop }}$ is the loss of the resonant loop of the magnetic resonant tank. It shows that the efficiency of the inverter/rectifier with uncoupled windings is increased by about $0.6 \%$ for the same magnetic cores. While the estimated $\eta_{i n v}$, $\eta_{r e c}$ increases to $95.2 \%$ for the optimized inductor with coupled windings.

3) Harmonic Currents: Fig.16 shows the measured winding currents, i.e., $i_{i n 1}$. By coupling the windings of the integrated inductor, the winding current amplitudes are much lower. As shown in Fig.16b, the amplitude of the second-order harmonic current is distinctly reduced from $1.89 \mathrm{~A}$ to $0.58 \mathrm{~A}$ at $300 \mathrm{~W}$. Fig. 17 is the FFT results of the input currents, i.e., $i_{i n}$. it shows that the second-order harmonic $(6 \mathrm{MHz})$ of the input current is also far lower than before. In this example, the amplitude (0.8A) is about $27 \%$ of that $(2.99 \mathrm{~A})$ with uncoupled windings. In additions, when the windings are uncoupled, the fundamental harmonic ripple is not canceled completely due to the slight difference in the winding inductance. Note that the measured results, which are not illustrated, for the rectifiers are similar to that of the inverters.

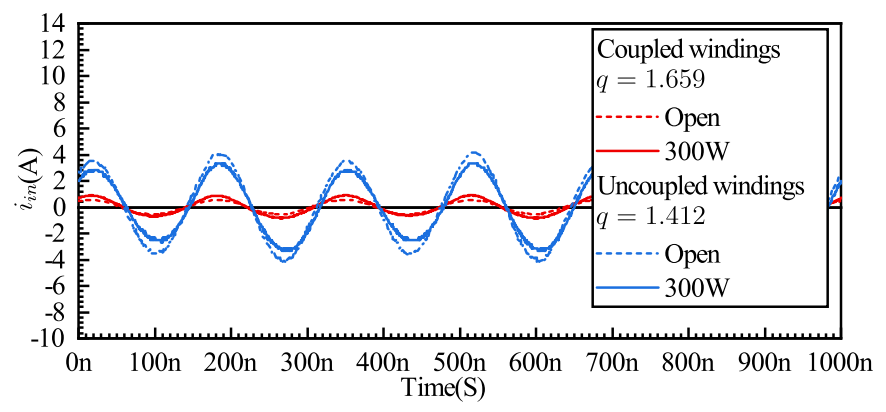

(a) Measured $i_{\text {in }}$ (AC components)

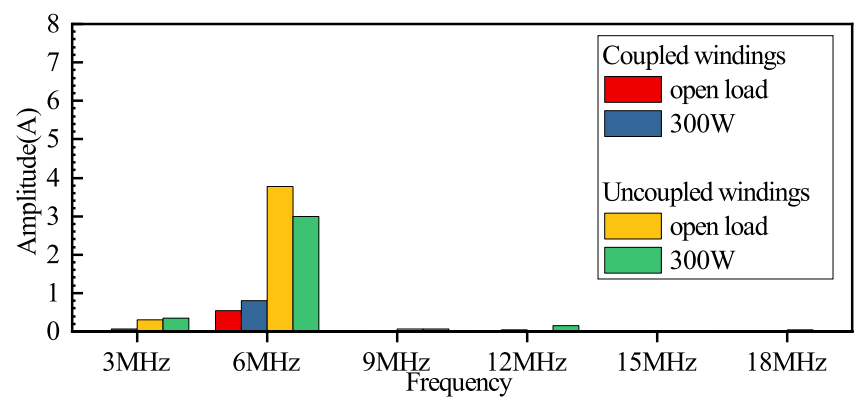

(b) FFT results for $i_{i n}$

Fig. 17. Measured ripples of input currents $\left(i_{i n}\right)$. 
Therefore, although the efficiency is not improved by coupling the windings of the integrated inductors, it can naturally balance the winding currents of the class-E inverters and rectifiers, and significantly suppress the harmonic currents without using EMI filters.

\section{CONCLUSION}

This paper focuses on the circuit design and magnetic integration of push-pull class-E inverters for the wireless power transfer up to megahertz. The design criterion is proposed to achieve ZVS of class-E inverters with coupled windings. In addition, the approach of magnetic integration is implemented. The new magnetic structure with hybrid magnetic materials is proposed to build the integrated inductors of the class-E inverters with either coupled windings or uncoupled windings. The following conclusions can be made:

1) By using the design criterion proposed, the class-E inverters with coupled windings maintain ZVS when the load resistance varies from the rated value to infinity without using any closed-loop control.

2) The integrated inductor with uncoupled windings can reduce the core loss slightly. In contrast, the integrated inductors with coupled windings can suppress the harmonic currents without using filters. In the experiment, the amplitude of the second-order harmonic current through the DC source is reduced to $27 \%$.

3) The core losses of the class-E inverter with coupled windings are higher than that with uncoupled windings. In the experiment, the system efficiency decreases by $0.5 \%$.

4) The winding currents of the rectifier with coupled windings are self-balanced, thus it provides a more stable output voltage.

5) The proposed magnetic structure with hybrid materials reduces the number of the gaps of the integrated inductor and simplifies the magnetic design of class-E inverters with coupled windings.

\section{REFERENCES}

[1] Z. Zhang, H. Pang, A. Georgiadis, and C. Cecati, "Wireless power transfer-an overview," IEEE Trans. Power Electron., vol. 66, no. 2, pp. 1044-1058, 2019.

[2] C. Zhang, D. Lin, and S. Y. R. Hui, "Ball-joint wireless power transfer systems," IEEE Trans. Power Electron., vol. 33, no. 1, pp. 65-72, 2018.

[3] Y. J. Park, B. Jang, S. M. Park, H. C. Ryu, S. J. Oh, S. Y. Kim, Y. Pu, S. S. Yoo, K. C. Hwang, Y. Yang, M. Lee, and K. Y. Lee, "A triple-mode wireless power-receiving unit with $85.5 \%$ system efficiency for a4wp, wpc, and pma applications," IEEE Trans. Power Electron., vol. 33, no. 4, pp. 3141-3156, 2018.

[4] T. Kan, R. Mai, P. P. Mercier, and C. C. Mi, "Design and analysis of a three-phase wireless charging system for lightweight autonomous underwater vehicles," IEEE Trans. Power Electron., vol. 33, no. 8, pp. $6622-6632,2018$

[5] C. Xiao, D. Cheng, and K. Wei, "An lcc-c compensated wireless charging system for implantable cardiac pacemakers: Theory, experiment, and safety evaluation," IEEE Trans. Power Electron., vol. 33, no. 6, pp. 4894-4905, 2018

[6] S. Aldhaher, D. C. Yates, and P. D. Mitcheson, "Load-independent class e/ef inverters and rectifiers for mhz-switching applications," IEEE Trans. Power Electron., vol. 33, no. 10, pp. 8270-8287, 2018.

[7] A. Grebennikov, "Switched-mode rf and microwave parallel-circuit class e power amplifiers," Int. J. RF and Microw. Comput.-Aided Eng., vol. 14, no. 1, p. 21-35, 2004.
[8] L. Roslaniec, A. S. Jurkov, A. A. Bastami, and D. J. Perreault, "Design of single-switch inverters for variable resistance /load modulation operation," IEEE Trans. Power Electron., vol. 30, no. 6, pp. 3200-3214, 2015.

[9] H. Mousavian, S. Abnavi, A. Bakhshai, and P. Jain, "A push-pull class e converter with improved pdm control," in Proc. IEEE 7th Int. Symp. Power Electron. Distributed Generation Syst., Jun. 2016, pp. 1-6.

[10] Z. Kaczmarczyk and W. Jurczak, "A push-pull class-e inverter with improved efficiency," IEEE Trans. Ind. Electron., vol. 55, no. 4, pp. $1871-1874,2008$

[11] M. d. Rooij and Y. Zhang, "Comparison of $6.78 \mathrm{mhz}$ amplifier topologies for 33w, highly resonant wireless power transfer," in Proc. PCIM Asia, Jun. 2017, pp. 1-7.

[12] H. Xiaosheng and C. Wei, "Wpt topology scheme with dual parallelcircuit class e inverters and integrated inductor," in Proc. IEEE Int. Electron. App. Conf. Exposition, Nov. 2014, pp. 635-638.

[13] M. Fu, H. Yin, M. Liu, Y. Wang, and C. Ma, "A $6.78 \mathrm{mhz}$ multiplereceiver wireless power transfer system with constant output voltage and optimum efficiency," IEEE Trans. Power Electron., vol. 33, no. 6, pp. 5330-5340, 2018.

[14] D. K. Saini, A. Ayachit, A. Reatti, and M. K. Kazimierczuk, "Analysis and design of choke inductors for switched-mode power inverters," IEEE Trans. Power Electron., vol. 65, no. 3, pp. 2234-2244, 2018

[15] Z. Zhang, K. D. T. Ngo, and J. L. Nilles, "Design of inductors with significant ac flux," IEEE Trans. Power Electron., vol. 32, no. 1, pp. 529-539, 2017

[16] M. Liu, M. Fu, and C. Ma, "Parameter design for a 6.78-mhz wireless power transfer system based on analytical derivation of class e currentdriven rectifier," IEEE Trans. Power Electron., vol. 31, no. 6, pp. 42804291, 2016.

[17] S. Park and J. Rivas-Davila, "Duty cycle and frequency modulations in class-e dc-dc converters for a wide range of input and output voltages," IEEE Trans. Power Electron., vol. 33, no. 12, pp. 10 524-10 538, 2018.

[18] M. Liu, Y. Qiao, S. Liu, and C. Ma, "Analysis and design of a robust class $e^{2}$ dc-dc converter for megahertz wireless power transfer," IEEE Trans. Power Electron., vol. 32, no. 4, pp. 2835-2845, 2017.

[19] S. Liu, M. Liu, S. Yang, C. Ma, and X. Zhu, "A novel design methodology for high-efficiency current-mode and voltage-mode classe power amplifiers in wireless power transfer systems," IEEE Trans. Power Electron., vol. 32, no. 6, pp. 4514-4523, 2017.

[20] S. Liu, M. Liu, S. Han, X. Zhu, and C. Ma, "Tunable class $e^{2} \mathrm{dc}-\mathrm{dc}$ converter with high efficiency and stable output power for $6.78-\mathrm{mhz}$ wireless power transfer," IEEE Trans. Power Electron., vol. 33, no. 8, pp. 6877-6886, 2018.

[21] S. Aldhaher, P. C. K. Luk, and J. F. Whidborne, "Tuning class e inverters applied in inductive links using saturable reactors," IEEE Trans. Power Electron., vol. 29, no. 6, pp. 2969-2978, 2014.

[22] M. H. Ahmed, C. Fei, F. C. Lee, and Q. Li, "48-v voltage regulator module with pcb winding matrix transformer for future data centers," IEEE Trans. Ind. Electron., vol. 64, no. 12, pp. 9302-9310, 2017.

[23] C. Fei, Y. Yang, Q. Li, and F. C. Lee, "Shielding technique for planar matrix transformers to suppress common-mode emi noise and improve efficiency," IEEE Trans. Ind. Electron., vol. 65, no. 2, pp. 1263-1272, 2018.

[24] A. A. Khan, H. Cha, and H. Kim, "Magnetic integration of discretecoupled inductors in single-phase direct pwm ac-ac converters," IEEE Trans. Power Electron., vol. 31, no. 3, pp. 2129-2138, 2016.

[25] A. Ayachit and M. K. Kazimierczuk, "Steinmetz equation for gapped magnetic cores," IEEE Magnetics Letters, vol. 7, pp. 1-4, 2016.

[26] J. Muhlethaler, J. Biela, J. W. Kolar, and A. Ecklebe, "Core losses under the dc bias condition based on steinmetz parameters," IEEE Trans. Power Electron., vol. 27, no. 2, pp. 953-963, 2012.

[27] C. P. Steinmetz, "On the law of hysteresis," Proceedings of the IEEE, vol. 72 , no. 2 , pp. $197-221,1984$ 


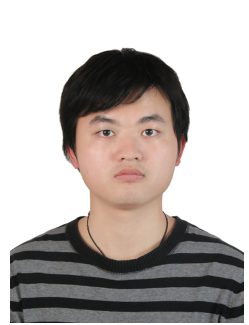

Xiaosheng Huang received his B.E. and Ph.D. degree in 2009 and 2015 from Fuzhou University, Fuzhou, China respectively. He is presently working as an associate professor in the College of Information Science and Engineering, Fujian University of Technology, Fuzhou, China. He is also with the Fujian Provincial University Engineering Research Center for Industrial Automation, Fujian University of Technology. He is a member of the Magnetic Component Specialty Committee of CPSS (China Power Supply Society). His current research interests include power conversion, high-frequency magnetics, wireless power transfer, and electromagnetic field analysis and applications.

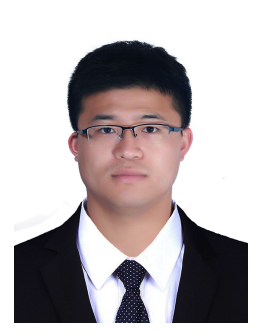

Yipeng Kong received the B.E. degree in 2016 from Suzhou University, Anhui, China. He is currently working toward the M.E. degree in Electrical Engineering from the College of Information Science and Engineering, Fujian University of Technology, Fuzhou, China. His research interests include highfrequency magnetics and wireless power transfer.

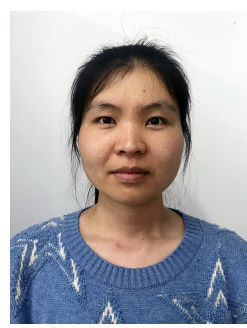

Shuyi Lin received the B.E. and Ph.D. degree in 2008 and 2014 from Fuzhou University, Fuzhou, China respectively. She is presently working as an associate professor in the College of Information Science and Engineering, Fujian University of Technology, Fuzhou, China. She is also with the Fujian Provincial University Engineering Research Center for Industrial Automation, Fujian University of Technology. Her current research interests include power conversion, high-frequency magnetics, wireless power transfer.

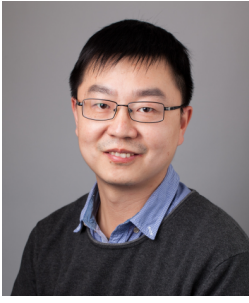

Ziwei Ouyang (S'07, M'11, SM'17) received his $\mathrm{PhD}$ degree from Technical University of Denmark (DTU) in 2011. From 2011 to 2013, he was a postdoc researcher at DTU. From 2013 to 2016, he was appointed as an assistant professor at the same department. Since from April 2016, he is an associate professor at DTU. His research areas focus on high-frequency planar magnetics modeling and integration, high-density high efficiency power converters, PV battery energy storage system, and wireless charging etc. He is IEEE senior member. He has over 70 high impact IEEE journal and conference publications, co-author on a book chapter on Magnetics for the "Handbook of Power Electronics" and currently he is the holder of 8 international patents. $\mathrm{He}$ was a recipient of Young Engineer Award at PCIM Asia 2014, and received Best Ph.D. Dissertation of the Year Award 2012 in Technical University of Denmark. He received several Best Paper Awards in IEEE sponsored international conferences. He has been invited to give lectures in many universities, enterprises and educational seminars and workshops around the world including USA, Europe and China. He has served as session chair in some IEEE sponsored conferences and associated editor for IEEE Journal of Emerging and Selected Topics in Power Electronics.

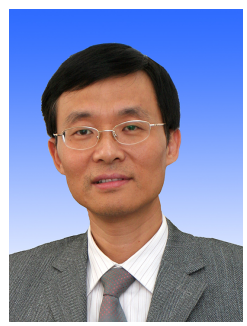

Wei Chen received his M.S. and Ph.D. degrees from Fuzhou University, Fuzhou, China, in 1987 and 1990, respectively. He worked as a Senior Visiting Professor in the Center for Power Electronics Systems (CPES), Virginia Tech, Blacksburg, VA, USA, from 1996 to 1998. He was with Delta Electronics Co. Ltd. as R\&D Manager in the Delta Power Electronics Center, Shanghai, China, from 1999 to 2008. He is presently working as a Professor in the College of Electrical Engineering and Automation, Fuzhou University. He is an Executive Member of the Council of CPSS (China Power Supply Society) and he served as the Chairman of the Magnetic Component Specialty Committee of CPSS. He has published more than 80 technical papers including IEEE Transactions and Proceedings. He has held more than 40 approved patents in both China and USA. His current research interests include power conversion, highfrequency magnetics, EMI debugging and solutions, wireless power transfer, and electromagnetic field analysis and applications. 